\title{
Üniversite Öğrencilerinin Teknolojik Ürünler Kullanabilmesinin Muhasebe ve Finansman Derslerine Etkisi: Kırgızistan-Türkiye Manas Üniversitesi İşletme Bölümü Öğrencileri Üzerinde Bir Araştırma*
}

\author{
The Effect of University Students' Use of Technological Products on Accounting and Finance Courses: A Study on \\ Business Administration Students of Kyrgyzstan-Turkey Manas University
}

\author{
Emin Yürekli ${ }^{1^{* *}}$ (D) Nevzat Tetik ${ }^{2}$ \\ ${ }^{1}$ Department of Accounting, Pamukkale University, Denizli, Turkey \\ ${ }^{2}$ Department of Business Administration, Inonu University, Malatya, Turkey
}

\begin{abstract}
Received: 07.07.2021
Accepted: 22.12 .2021

This article was checked by intihal.net

Öz

İşletme yöneticileri her alanda olduğu gibi, muhasebe-finansman alanında da en güncel bilgiler ile donatılmış ve bu alandaki teknolojileri optimal düzeyde kullanabilen insan kaynağını büyük önem vermektedir. Özellikle Covid-19 ile birlikte tüm dünyada yüksek oranda teknoloji ve teknolojik ürün kullanımı yaygınlaşmış olup bu durum teknolojinin hızla ilerlemesi ve gelişmesini de beraberinde getirmiştir. Dünya'nın neresinde çalışıır ise çalışılsın mutlak düzeyde yüksek teknolojiyi kullanma zorunluluğu ortaya çıkmaktadır. Bu bağlamda çalışmanın amacı, üniversite öğrencilerinin teknolojik ürünleri kullanabilmesinin muhasebe ve finansman derslerine etkilerinin araştırılmasıdır. Kırgızistan-Türkiye Manas Üniversitesi İktisadi ve İdari Bilimler Fakültesi işletme bölümünde öğrenim gören 98 öğrenci üzerinde yapılan araştırmada, öğrencilere önceden hazırlanmış olan dokuz açık uçlu sorular sorulmuş olup verilen cevaplar derinlemesine araştırma yöntemine göre yorumlanmıştır. Çalışmadan çıkan sonuca göre öğrencilerin çok fazla teknolojik ürünler kullanmadığı büyük bir çoğunluğun benzer ürünleri kullandığı bulgusuna ulaşılmıştır. Sonuç olarak ders müfredatlarına çok daha farklı teknolojik ürünlerin kullanıldığı ve öğretildiği dersler konularak öğrencilerin bu alandaki birikimleri ve tecrübeleri zenginleştirilebilir. Yüksek teknolojiler ile donatılmış laboratuvar ortamlarının geliştirilmesi ve kullanılması yaygınlaştırılabilir.
\end{abstract}

Anahtar kelimeler: Muhasebe, Finansman, Teknolojik ürünler

\section{Abstract}

Human resources, which are equipped with the contemporary knowledge and which are efficient users of technology, are vital for the department of accounting and finance like in other departments of companies. Especially, after the pandemic, the substantial extension of high technology usage and inevitable improvement of technology level throughout the world brought about higher necessity for qualified human resources. In this context, the aim of the study is to investigate the effects of university students' ability to use technology on accounting and finance courses. For this reason, a survey is conducted for 98 students at the Faculty of Economics and Administrative Sciences of Kyrgyzstan-Turkey Manas University. Students give answers to nine open-ended questions. The answers are interpreted by applying the indepth interview method. According to the results, it can be derived that the students do not use different kinds of technological devices or programs and the majority of them use similar tools. As a suggestion for education systems, it would be crucial for future human resources to include technology-oriented courses in curriculums. In addition, it would be better to found laboratories with high technology in order to enable students to practice enough and if possible, to reach further developments.

Keywords: Accounting, Finance, Technological products

Yürekli, E. \& Tetik, N. (2021). Üniversite Öğrencilerinin Teknolojik Ürünler Kullanabilmesinin Muhasebe ve Finansman Derslerine Etkisi: Kırgızistan-Türkiye Manas Üniversitesi İşletme Bölümü Öğrencileri Üzerinde Bir Araştırma. Journal of Academic Value Studies, 7(4), 438-442. http://dx.doi.org/10.29228/javs.52027

\footnotetext{
* Bu makale, 9-11 Haziran 2021 tarihlerinde Bişkek/Kırgızistan'da gerçekleştirilen 2. Uluslararası iktisadi ve Idari Bilimler Kongresi'nde sözlü olarak sunulan özet bildirinin genişletilmiş halidir.
}

**E-mail: eyurekli@pau.edu.tr (Corresponding Author) 


\section{Giriş}

Dünyada yaşanan çok hızlı teknolojik gelişmeler özellikle Endüstri 4.0 devrimi ile birlikte fevkalade büyük bir ivme kazanmıştır. Küresel çapta yaşanan bu çok hızlı teknolojik gelişme ve ilerlemeler işletmelerin neredeyse tüm birimlerinde ve sistemlerinde kendisini göstermiştir. Bu gelişmeler muhasebe-finansman bilgi sistemini de çok yakından ilgilendirmektedir. Özellikle muhasebe uygulamalarında muhasebe yazılım programları kullanılmaya başlanmasıyla birlikte dijital teknoloji daha fazla kullanılmaya başlanmış ve günümüze e-defter, e-fatura, e-beyanname olarak hayatımıza girmiştir.

Diğer taraftan, günümüzde muhasebe meslek mensuplarından beklenen sadece olayın teknik boyutunu oluşturan muhasebe kayıtlarının yapılması değildir. Aynı zamanda elde edilen verilerin teknolojik araç ve yöntemlerle analiz ve değerlendirilmesinin yapılarak ulaşılan bulguların işletme faaliyetlerinde kullanılması da gerekmektedir. Dolayısıyla ilgili bilim dallarında yaşanan tüm teknolojik ilerleme ve gelişmeleri muhasebe meslek mensuplarının yakından takip ederek uyum sağlaması zorunludur. Bu bağlamda muhasebe meslek mensuplarının iş hayatlarına başlamadan önce almış oldukları eğitim sırasında muhasebe ve finansman derslerinin teknoloji destekli olup olmadıkları büyük önem kazanmaktadır. İlgili derslerin teknoloji destekli olması muhasebe meslek mensuplarının mesleklerini uygularken teknolojiye uyum sağlamaları kolaylaşacaktır.

Bu çalışma ile üniversite öğrencilerinin teknolojik ürünler kullanabilmesinin muhasebe ve finansman derslerine etkisi araştııılmak istenmiştir. Kırgızistan-Türkiye Manas Üniversitesi İktisadi ve İari Bilimler Fakültesi işletme bölümünde öğrenim gören 98 öğrenciye önceden hazırlanmış olan dokuz açık uçlu sorular sorulmuştur. Öğrencilerden alınan cevaplar çerçevesinde elde edilen bulgular derinlemesine araştırma yöntemine göre değerlendirilerek yorumlanmıştır.

\section{Literatür Taraması}

Literatür çalışması sonuçlarında elde edilen sonuçlar genel olarak; öğrencilerin eğitim süreci boyunca bilgi teknolojisi araçları kullanımının eğitim süreçlerini olumlu etkiledikleri görülmüştür. Bu alanda yapılan çalışmalar ağırlıklı olarak muhasebe bilim dalı üzerinde yoğunlaşmıştır. Yapılan bu çalışma da ise muhasebe-finansman dersleri bir bütün olarak kabul edilmiştir. Bunun temel gerekçesi olarak da muhasebe ve finansman derslerinin birbirini tamamlar nitelikte olduğu düşünülmektedir. Diğer önemli bir gerekçesi de bazı derslerin örneğin mali tablolar analizi, denetim ve revizyon gibi derslerin kimi zaman muhasebe kimi zaman ise finansman öğretim üyeleri tarafından verildiği gözlenmekte ve müfredatta farklı bilim dallarında yer aldığı gerekçesidir.

Ahadiat, N. (2003). Çalışma farklı bölümlerde okuyan öğrencilere verilen muhasebe derslerinde ki teknolojiyi kullanma etkinliği ve önemi anket ve karşılıklı mülakatlarla yapılmıştır. Elde edilen bulgulara göre; diğer derslerde belirli derecede teknoloji kullanıldığını gözlemlemiş, ancak muhasebe derslerinde durumun biraz daha farklı olduğu görülmüştür

Jebeile ve Abeysekera (2010). Çalışmanın amacı, Avustralya'da eğitim gören muhasebe öğrencilerine yönelik muhasebeye giriş kursunda interaktif çevrimiçi bilgisayar destekli eğitim modülünün başlatılmasını değerlendirmektir. Elde edilen bulguya göre, nakit akım tablosu düzenlemekte güçlük çeken öğrencilerin büyük çoğunluğunun söz konusu modülü kullanarak yaptıkları hataları görme olanağına kavuşacakları ve böyleikle mali tablolar düzenleyebilecekleri sonucuna ulaşılmışdır.

Chrismastuti ve Purnamasari (2015). Çalışmada; muhasebe eğitiminde bilgi teknolojilerinin çıktıya yani öğrenci başarısına etkisi incelenmiştir. Sonuç olarak teknoloji kullanımı derslerin daha kolay algılanması ve derslerdeki başarıyı daha çok artıracağı sonucuna ulaşılmıştır.

Fidan vd (2015). Yapılan çalışmada i.i..B.F. öğrencilerinin aldılaşrı eğitim süresince teknolojiden ne denli faydalandıkları ve bu konudaki görüşlerini ortaya görüşlerini ortaya koymaları amaçlanmıştır. Ampirik çalışmada, öğrenciler muhasebe derslerinde kesinlikle pc, muhasebe yazılım programı kullanılması gerektiğinin belirtmişlerdir.

Hatunoğlu, Z. (2006). Çalışmada Türkiye'de lisans seviyesinde muhasebe eğitiminde öğretme teknikleri ve bilgi teknolojisi kullanımı belirlenmeye çalışıııştır. Bu bağlamda araştırmanın amacı, öğrencilerin üniversitelerimizde verilen muhasebe eğitiminin mevcut durumu ve olması gereken düzeyini ders sunumu açısından değerlendirmelerini saptamaktır. Araştırmanın ana kütlesini Türkiye'de bulunan 53 devlet, 24 vakıf üniversitesi olmak üzere toplam 77 üniversitenin, i.i..B.F. ve İşletme Fakülteleri'nde işletme ve iktisat bölümlerinde öğrenim gören öğrenciler oluşturmaktadır. Anket soruları üniversitelere 15 Nisan 2005 tarihinde ulaşacak şekilde gönderilmiştir. Her fakülteye 50 
adet anket gönderilmiş ve bu şekilde toplam 951 kişi örnekleme girmiştir. Araştırmada veri toplama aracı olarak anket kullanılmıştır. Üç bölümden oluşan anket, birinci bölümü demografik özellikler, ikinci bölümü muhasebe eğitiminin mevcut ve gelişimine ilişkin önermeler, üçüncü bölümü ise muhasebe derslerinde bilgi teknolojisi kullanımına ilişkin önermelerin yer aldığı sorulardan oluşmaktadır. Elde edilen bulgulara göre, üniversitelerde verilen muhasebe eğitimindeki derslerde bilgi teknolojisi kullanımı, sadece bilgileri yansıtma ve öğrencilerin oradan takibi şeklinde değil de öğrenciye düşünme, tartışma ve kullanma imkanı verecek tarzda, eğitimin etkinliğini artıracak bir araç olarak gerçekleştirilmelidir.

Temelli, F. (2019). Bu çalışmada ise, İktisadi ve İdari Bilimler Fakültesinde okuyan öğrencilerin almış oldukları muhasebe derslerinde teknolojiden ne kadar yararlandıkları ve bu konuda öğrencilerin görüşleri yer almıştır. Çalışmanın sonucunda öğrencilerin teknolojik ders materyali kullanma puanları bölüm değişkenine göre anlamlı farklılık göstermiştir. Muhasebe derslerinde bilgi ve iletişim teknolojilerinden, sunum amaçlı faydalanmanın daha çok ötesinde bu alanda daha fazla başarılı olabilmek için farklı amaçlar içinde yararlanılması gerekmektedir.

\section{Uygulama}

Çalışmanın bu bölümünde; araştırmanın önemi, hedef kitlesi, yöntemi, bulguları ve elde edilen verilerin değerlendirilmeleri yer almaktadır.

\subsection{Araştırmanın Amacı ve Önemi}

Muhasebe ve finansman eğitiminde teknolojik ürünler kullanımının bu derslere olan etkileri oldukça önemli bir yere sahiptir. Bu çalışmada üniversite öğrencilerinin teknolojik ürünler kullanabilmesinin muhasebe ve finansman derslerine olan etkileri öğrencilerin bakış açıları çerçevesinde tespit edilmeye çalışılmıştır. Araştırma konusu ile ilgili öğrencilere birtakım açık uçlu sorular sorulmuştur. Öğrencilerin vermiş oldukları cevaplar çalışmada herhangi bir değişiklik yapılmadan aynen yer almaktadır.

\subsection{Araştırmanın Hedef Kitlesi}

Bu araştırma Kırgızistan-Türkiye Manas Üniversitesi i.i.B.F. İşletme bölümü öğrencileri üzerinde yapılmıştır. Toplam 98 öğrenciye soru formları gönderilmiş, ancak 61 öğrenciden cevap gelmiştir. Gelen cevapların bazıları boş veya bilimsel değerlere uygun olmayıp sadece 47 tanesi değerlendirme kapsamına alınmıştır.

\subsection{Araştırmanın Yöntemi}

Bu araştırmada öğrencilere dokuz tane açık uçlu sorular sorulmuş olup, öğrencilerden gelen cevaplar derinlemesine araştırma yöntemi kurallarına göre analiz edilerek değerlendirilmiştir.

\section{Bulgular}

"Üniversite Öğrencilerinin Teknolojik Ürünler Kullanabilmesinin Muhasebe ve Finansman Derslerine Etkisi: Kırgızistan-Türkiye Manas Üniversitesi İşletme Bölümü Öğrencileri Üzerinde Bir Araştırma" başıkılı çalışmanın açık uçlu soruları ve elde edilen bulgular aşağıda sistematik olarak sıralanmıştır.

Soru1) Hangi teknolojik ürünler sizlerin muhasebe derslerini anlamanızda daha yararlı olur?

- $\quad$ Teknolojik ürünle falan uğraşacak zaman değil bir an önce okulları açın dersleri anlamıyoruz.

- Bilgisayar

- Projeksiyon

- $\quad$ Akıllı Tahta

- Tablet

Soru 2) Hangi teknolojileri biliyor veya kullanabiliyorsunuz.

- Bilgisayar ve Telefon

- Bilgisayar, telefon, notebook

Tablet 
Soru 3) Muhasebe derslerinde kullanılmasını düşündüğünüz teknolojik araçlar hakkındaki düşünceleriniz nelerdir?

Muhasebe derslerini genellikle uygulamalarla daha iyi anlayabiliyoruz. O yüzden teknolojilerle kendimiz uygulamaları yaparak ya da öğretmen ile adım adımlarla yaparsak iyi anlaşılır.

Soru 4) Muhasebe derslerinde kullanılması gereken teknolojik yazılımlar hakkındaki düşünceleriniz nelerdir.?

- Muhasebe paket programları

$-\quad 1 C$

- $\quad$ Başka muhasebe yazııımları varsa onları da mutlaka öğrenmek isteriz.

Soru 5) Önermiş olduğunuz teknolojik yazılım sizce yeterli mi?

- Yazııım teknolojiler hakkında bilgilerim az olduğu için yetersiz olabilir.

- Çok fazla bilgim yok

Soru 6) Teknoloji kullanımı hakkında düşünceleriniz nelerdir?

- Birçok programlar var ama onları öğrenmek ve pratik yapmak gerekiyor ve ona göre sonuçları olur.

- Çok avantajları vardır. Bir şey anlamadığım anda ya da derse gelemediğimde videoları izleyebilirim. Kütüphanede bulamadığım kitaplara kolayca ulaşabilirim vb.

- $\quad$ Ders çalışmamda veya dersleri anlamamda bana çok yardımcı olur.

Soru 7) Teknolojik ürünlerin kullanımı muhasebe derslerini anlamayı ne derecede kolaylaştııır?

- $\quad$ Eğer kullanabilirsek yüksek derecede başarı sağlanır.

- $\quad$ Teori ile uygulamayı birleştirir diye düşünüyorum, bence çok yararlı olur.

- Muhasebe derslerinde uygulama çok fazla olduğu için teknoloji ile birlikte bu uygulamaları yapabilir ise dersi daha iyi anlarız diye düşünüyorum.

Teknolojik ürünlerin kullanımı muhasebe derslerini anlamayı kolaylaştııır.

Soru 8) Muhasebe derslerinin mi yoksa Finansman derslerinin mi anlatımında mı daha çok teknolojik destekli olmasını tercih edersiniz?

Muhasebe

İkisi de uygulamalı ders olduğu için teknolojik destekli olması çok önemlidir

Muhasebe ve Finansman

Soru 9) Finans laboratuvarları ve işlevleri hakkında bilginiz var mı?

Hayır (Öğrencilerin tamamı)

\section{Sonuç}

Muhasebe-Finansman eğitiminde asıl amaç, öğrencilere özellikle iş hayatlarında gerek teorik gerekse pratik boyutlarıyla yararlı olabilecek bilgi ve tecrübelerin belirli bir müfredat altında sistematik olarak aktarılmasıdır. Bu nedenle eğitim sırasında derslerde kullanılan materyaller de derslerin daha iyi anlaşılır ve etkili olması açısından önemli olmaktadır. Bu çalışmada, öğrencilerin teknolojik ürünler kullanabilmesinin muhasebe ve finansman derslerine olan etkileri öğrenciler tarafından değerlendirilmeye çalışımıştır. Öğrencilerin vermiş oldukları cevaplara göre bilgisayar, akıllı tahta ve tablet kullanımı öğrencilerin muhasebe derslerini anlamalarında daha yardımcı olduğu görüşü hakimdir. Teknolojik yazılım aracı olarak en fazla $1 \mathrm{C}$ programını kullandıklarını belirtmişler, bazı öğrenciler ise 1C programı dışında başka muhasebe paket programını öğrenmek istemektedirler. Öğrencilere sorulan muhasebe derslerinde teknolojik ürünlerin kullanımı muhasebe derslerini anlamayı ne derecede kolaylaştııı sorusuna ise öğrencilerin çok büyük çoğunluğu eğer kullanabilirsek yüksek derecede başarı sağlanır, teori ile uygulamayı birleştirir diye düşünüyorum, bence çok yararlı olur, muhasebe derslerinde uygulama çok fazla olduğu için teknoloji ile birlikte bu uygulamaları yapabilir ise 
dersi daha iyi anları diye düşünüyorum, Öğrencilerin çok büyük çoğunluğunun genel bir görüşü ise, teknolojinin dersi sevdirdiği ve derslere devam etmeyi kolaylaştırdığı için daha akılda kalıcı olduğunu belirtmişlerdir.

Ampirik çalışmada elde edilen bulgular yerli ve yabancı literatür de yer alan çalışmaların sonuçları ile büyük bir benzerlik göstermektedir. E-defter, e-fatura, e-ticaret gibi devrimsel nitelikte teknolojinin yoğun bir şekilde kullanıldığı günümüzde artık yeni yetişen neslin bilgi ve iletişim sistemlerini daha sağlıklı ve aktif olarak kullanabilme yeterliliğine sahip olmaları gerekliliği bir kez daha ortaya çıkmaktadır. Gelişime ve yeniliklere açık yeni oluşumlara cevap vermeye hazır bir muhasebe-finansman eğitimi için öncelikle öğretim üyelerinin her türlü teknolojik araç ve gereç ile donanımlı bir şekilde dersleri yürütebilecek yetkinlikte olmalarıyla birlikte üniversitelerin de gerekli alt yapı, araç ve gereçlerin güncel teknoloji ile donatılmış olması arzu edilen amaçların gerçekleştirilmesinde zorunlu olduğu söylenebilir.

Bundan sonra akademik yazında yapılacak çalışmaların daha geniş ölçekte ve farkı bilimsel yöntemlerinin kullanılarak yapılması elde edilen bulguların sağlıklı ve rasyonel olmasını sağlamakla birlikte geliştirilecek önerilerin de isabetli ve yerinde olmasını da temin edecektir.

\section{Kaynakça}

Ahadiat, N. (2003). "Applications of Technology in Accounting Education and Analysis of Its Use Among Faculty", California State Polytechnic University, Pomona, Fall.

Chrismastuti, A.A. ve V. Purnamasari. (2015). "The Effectiveness of IT Usage in Accounting Education”, International Journal of Humanities and Management Sciences (IJHMS), 3(4) (2015) ISSN 2320-4044 (Online)

Fidan, M. E. ve Ş. Subaşı. (2015). “Türkiye'deki Muhasebe Öğretim Elemanlarının Sayısal Çağda Teknoloji Kullanımına ilişskin Durum Tespiti”, Çankırı Karatekin Üniversitesi Sosyal Bilimler Enstitüsü Dergisi, 6 (1), 85-112.

Hatunoğlu, Z. (2006). “Muhasebe Eğitiminde Bilgi Teknolojisi Kullanımının Sunum Kalitesine Olan Etkilerinin Tespitine Illişkin Bir Araştırma", Muhasebe ve Finansman Dergisi, Sayı: 30. 190-200.

Jebeile, S. ve I. Abeysekera I. (2010). "The Spread of ICT Innovation In Accounting Education". International Journal of Teaching and Learning in Higher Education, 22(2), 158-168.

Öztürk, S, Kutlu, H. (2017). “Muhasebe Eğitiminde Teknoloji Kullanılmasına Öğrencilerin Bakışı: Kafkas Üniversitesi’nde Bir Araştırma". Muhasebe Bilim Dünyası Dergisi, 19 (3) , 781-799. https://dergipark.org.tr/tr/pub/mbdd/issue/31332/307358

Temelli, F. (2019). "iiBF öğrencilerinin muhasebe derslerinde teknoloji kullanımı ile ilgili görüşleri: Ağrı ibrahim çeçen üniversitesi örneği”, Muhasebe Bilim Dünyası Dergisi, 20 (Özel Sayı), 701-720. 